\title{
First Report of Chrysanthemum (Chrysanthemum morifolium) Crown Rot Caused by Fusarium solani in Korea
}

\author{
Hye Yeon Mun, Je Yong Jeong, Chang Jeon Kim and Hyang Burm Lee* \\ Division of Applied Bioscience and Biotechnology, Chonnam National University, Gwangju 500-757, Korea \\ (Received on October 29, 2011; Revised on November 27, 2011; Accepted on November 27, 2011)
}

In August 2010, a severe crown rot was observed on chrysanthemum (Chrysanthemum morifolium Ramat., variety Sinro) in several greenhouses located at Damyang and Muan, Jeonnam province, Korea. Three isolates (EML-CHS1, -CHS2, and -CHS3) of Fusarium were isolated from the affected plants and identified based on morphological characteristics and rDNA internal transcribed spacer (ITS) sequence analysis. Sequence analysis by BLAST indicated that EMLCHS1, -CHS2 and CHS3 were closest to a Fusarium species, $F$. solani with $>99 \%$ sequence similarity. Pathogenicity tests were performed on chrysanthemum with spore suspensions containing $3.4 \times 10^{6}$ spores $/ \mathrm{ml}$ using the dipping method. Ten days after inoculation, similar symptoms to those observed in the greenhouses were seen on the inoculated plants. The causal fungus was reisolated from the artificially inoculated basal stems, fulfilling Koch's postulates. To our knowledge, this is the first report of crown rot by Fusarium solani on chrysanthemum (Chrysanthemum morifolium) in Korea.

Keywords : Asteraceae, rDNA sequence, outbreak, pathogenicity

Chrysanthemums are a genus (Chrysanthemum morifolium Ramat.) of about 30 species of perennial flowering plants in the family Asteraceae, which is native to Asia and northeastern Europe. In Korea, the cultivation area covers 700-800 ha and the annual monetary yield reaches approximately $\$ 400$ million. Generally, chrysanthemums are considered a beautiful cut flower in regards to its figure and fragrance. Also, some varieties of chrysanthemums have been used to make tea as well as a natural insect repellent. Chrysanthemum tea is a flower-based tisane made from chrysanthemum flowers of the species C. morifolium or C. indicum, which are highly popular in East Asia including China and Korea. The extracts of chrysanthemum plants (stem and flower) have been shown to have a wide variety of potential

\footnotetext{
*Corresponding author.

Phone) +82-62-530-2136, FAX) +82-62-530-2139

E-mail) hblee@jnu.ac.kr
}

medicinal properties, including anti-viral, anti-bacterial and anti-mycotic activities (Hu et al., 1994; Collins et al., 1997; Sassi et al., 2008; Marongiu et al., 2009).

In August 2010, a severe outbreak of wilt due to crown rot was observed on chrysanthemums (C. morifolium, variety Sinro) in several greenhouses located at Damyang and Muan, South Korea. To date, 7 viral, 10 fungal and 2 bacterial diseases on chrysanthemums have been reported in Korea. The literature concerning the major diseases on chrysanthemums in Korea have included phytophthora rot by Phytophthora cactorum, powdery mildew by Golovinomyces cichoracearum, rust by Puccinia tanaceti and verticillium wilt by Verticillium dahliae (KSPP, 2009). To date, 78 records of diseases caused by 23 Fusarium species including $F$. solani, $F$. oxysporum, $F$. poae, $F$. roseum and Fusarium sp. have been reported to cause stem or root rot and wilt on chrysanthemums (Farr and Rossman, 2011). Several records of stem rot or wilt on Chrysanthemum spp. by $F$. solani have been reported in the USA, Hongkong, Thailand, India and Papua New Guinea (Farr and Rossman, 2011).

The objectives of this study were to investigate the morphological characteristics of Fusarium species isolated from the crown rot lesion on chrysanthemums, identify the causal fungus based on rDNA internal transcribed spacer (ITS) sequence analysis, and evaluate its pathogenicity to chrysanthemum plant.

Occurrence of crown rot on chrysanthemum. In August 2010, a severe wilt due to crown rot was observed on chrysanthemums at greenhouses located at Damyang and Muan, Jeonnam province, Korea (Fig. 1). The disease outbreak ranged from $20 \%$ to $35 \%$ in affected greenhouses, causing an enormous economic loss for farmers. The early symptoms included slight wilt and brown to blackishbrown discoloration surrounding basal stems. The late symptoms included crown rot, root rot, wilting, leaf blight and dying plants. The infected surfaces often became covered with white tufts of spores and mycelia (Fig. 1C, D). When basal stems were split, they showed tan to brown discoloration inside (Fig. 1E). 


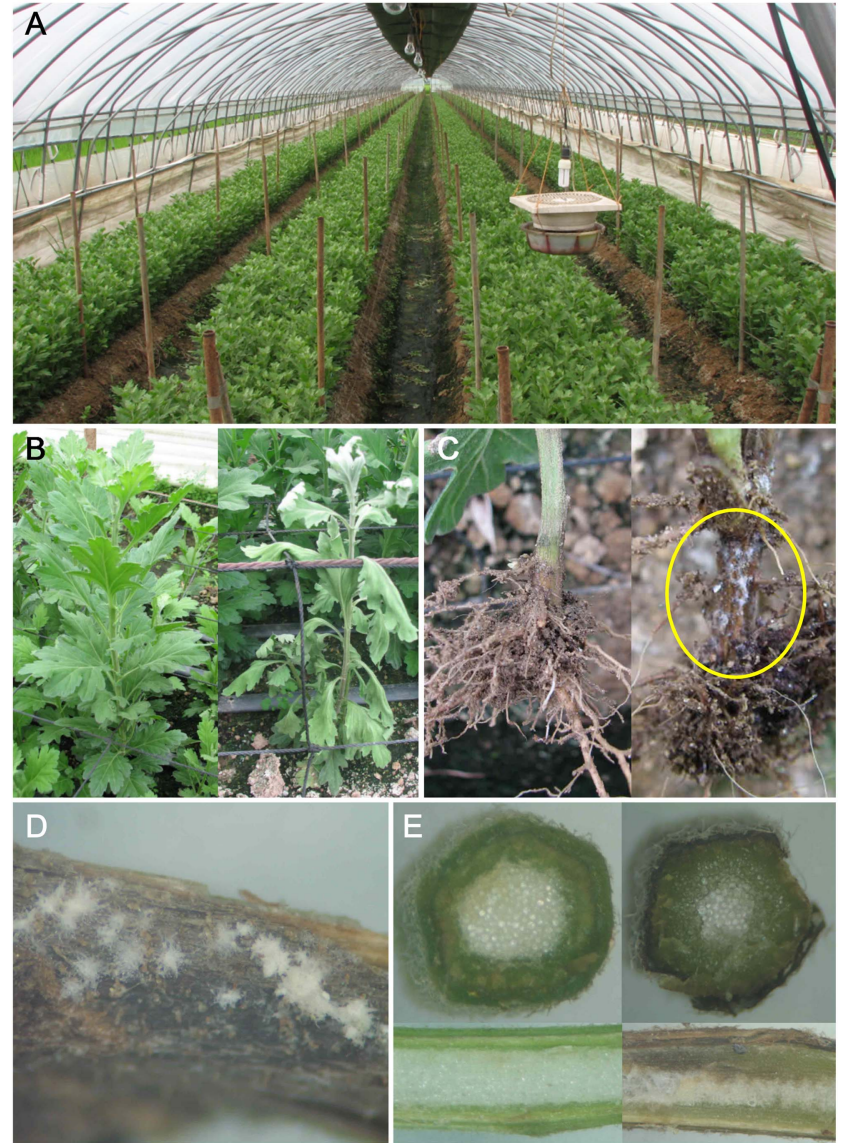

Fig. 1. Occurrence of crown rot on Chrysanthemum morifolium (variety Sinro) and morphology of the causal pathogen, Fusarium sp. EML-CHS1. (A) healthy chrysanthemum growing in the greenhouse, (B) typical wilt symptom due to crown rot (right) and healthy (left) chrysanthemum, (C) rot symptom on basal stem and root with white fungal mass (right, in yellow circle) and healthy stem (left), (D) infected basal stem covered with white mycelia and spores, (E) cutted stem healthy (left) and infected (right).

\section{Morphological characteristics of crown rot fungus.} Three isolates were asceptically isolated from the crown rot lesions of wilted chrysanthemums using a thin capillary tube and subcultured on PDA. The diseased basal stems were collected from the greenhouses and the fungal masses including spores and mycelia were directly taken from the lesions for slide preparation using a capillary tube. Microscopic examination of three representative samples (EMLCHS1, -CHS2 and-CHS3) was conducted to identify the pathogen based on references (Booth, 1971; Nelson et al., 1983). The specimens examined were deposited at EMLH (Environmental Microbiology Lab Herbarium, Chonnam National University, Gwangju, Korea). The microconidia was oval to kidney shaped and the conidia on the natural stem lesions were 13.8-24.3 (avg. 17.6) $\mu \mathrm{m}$ in length $\times$ 3.3-6.5 (avg. 5.2) $\mu \mathrm{m}$ in width. Macroconidia on natural lesions were slightly curved, falcate-shaped with 3-5 septa,

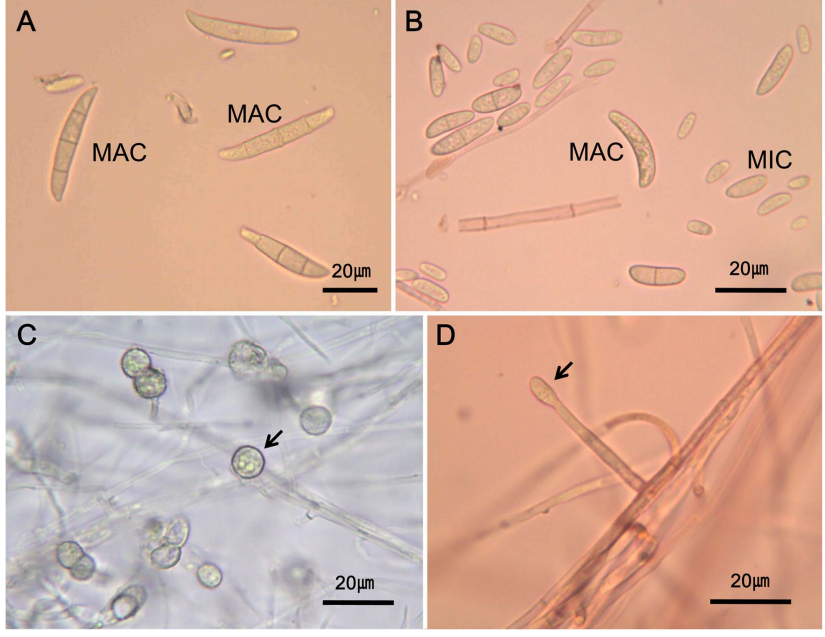

Fig. 2. Fusarium solani EML-CHS1 from crown rot lesion on $C$. morifolium. (A \& B) Macro-conidia (MAC) and microconidia (MIC) of F. solani formed on crown rot lesion of the basal stem, (C) chlamydospores (black arrow) and (D) phialide (black arrow) formed on PDA at $25^{\circ} \mathrm{C}$ for 7 days $(\times 400)$.

and the conidia were $30.4-43.3$ (avg. 36.3) $\mu \mathrm{m}$ in length $\times$ 3.9-6.2 (avg. 5.4) $\mu \mathrm{m}$ in width. Conidiophores were 43.982.9 (avg. 59.3) $\mu \mathrm{m}$ in length. The chlamydospores were globose, hyaline, smooth to rough and the diameter were 7.7-10.6 (avg. 9.0) $\mu \mathrm{m}$ (Fig. 2).

Molecular phylogenetic analysis of the crown rot fungus. To confirm the tentative identification based on the morphological characteristics, molecular analysis of internal transcribed spacer (ITS) rDNA sequences from the three representative isolates was performed. The isolates were cultured on PDA overlaid with cellophane. From the extracted genomic DNA, the complete ITS region including the 5.8S rDNA region was amplified with ITS5 (5'GGAAGTAAAAGTCGTAACAA-3') and ITS4 (5'-TCCTCCGCTTATTGATATGC-3') primers as described by Lee et al. (2006). Phylogenetic analyses based on the ITS sequences of Fusarium isolates were conducted, using BioEdit ver. 5.0.9.1, Clustal X ver. 1.83 (Thompson et al., 1997). Their phylogenies were assessed using 60 taxa (Table 1) by employing programs available in the MEGA 4 (Tamura et al., 2007). EML-CHS1 (accession number, HQ439150), EML-CHS2 (accession number, HQ439151) and EML-CHS3 (accession number, HQ439152) were completely matched to $F$. solani, which belongs to the $F$. solani species complex (Summerbell and Schroers, 2002), by BLASTN search (Fig. 3). The Neighbour-Joining (NJ) phylogenetic tree based on the ITS sequences of 60 taxa, including the three isolates obtained from diseased $C$. morifolium in Korea was constructed using. The percent sequence identity (the number of matches/the complete 
Table 1. Fusarium taxa used for molecular phylogenetic analysis in this study

\begin{tabular}{|c|c|c|c|c|}
\hline Taxon name & $\begin{array}{l}\text { Collection no. } \\
\text { (isolate no.) }\end{array}$ & Source (host) & Origin & $\begin{array}{l}\text { GenBank } \\
\text { accession no. }\end{array}$ \\
\hline Fusarium sp. & EML-CHS1* & Chrysanthemum morifolium & Korea & HQ439150 \\
\hline Fusarium sp. & EML-CHS2* & Chrysanthemum morifolium & Korea & HQ439151 \\
\hline Fusarium sp. & EML-CHS3* & Chrysanthemum morifolium & Korea & HQ439152 \\
\hline F. solani & $\mathrm{d} 16$ & $\mathrm{NI} * *$ & Netherlands & GQ922560 \\
\hline F. solani & Tul-1 & Roots of Cymbidium sp. & China & HM214456 \\
\hline F. solani & MAFF731042 & Daucus carota root & Japan & AB513851 \\
\hline F. solani & MOD-5 & NI & China & EU625405 \\
\hline F. solani & FMR7988 & Human keratitis & Brazil & AM412642 \\
\hline F. solani & FMR4391 & Human Blood & USA & AM412635 \\
\hline F. solani & SUF209 & Solanum tuberosum & NI & AF150466 \\
\hline F. solani & FMR7992 & Human keratitis & Brazil & AM412625 \\
\hline F. solani & FMR8688 & Nematode & Spain & AM412602 \\
\hline F. solani & FMR8340 & Human fungemia & Qatar & AM412594 \\
\hline F. solani & FMR7140 & Aquarium sand & Spain & AM412636 \\
\hline F. solani & NRRL22825 & Glycine max & NI & AF178419 \\
\hline F. solani & NRRL31156 & NI & NI & AY220236 \\
\hline F. solani & FMR7141 & Aquarium sand & Spain & AM412637 \\
\hline F. solani & FMR7985 & Human keratitis & Brazil & AM412641 \\
\hline F. solani & FMR7991 & Human keratitis & Brazil & AM412624 \\
\hline F. solani & NRRL22277 & Xanthoxylum sp. & NI & AF178401 \\
\hline F. solani & NRRL22142 & Cucurbita sp. & NI & AF178411 \\
\hline F. venenatum & $\mathrm{QP}$ & NI & USA & AF006359 \\
\hline F. venenatum & NRRL22198 & NI & Germany & AF006350 \\
\hline F. sambucinum & NRRL22187 & NI & Germany & U85540 \\
\hline F. sambucinum & NRRL22203 & NI & Germany & AF006346 \\
\hline F. sporotrichioides & NRRL25479 & NI & Netherlands & AF006348 \\
\hline F. sporotrichioides & FSU85541 & NI & USA & U85541 \\
\hline F. culmorum & OTU180 & NI & Canada & GU934521 \\
\hline F. culmorum & MAFF241212 & NI & NI & AB586990 \\
\hline F. culmorum & CBS122445 & Orthotomicus erosus & Spain & DQ655726 \\
\hline F. graminearum & LH184 & Camellia sinensis & China & HQ832817 \\
\hline F. graminearum & ATCC MYA-4620 & $\mathrm{NI}$ & USA & GU327636 \\
\hline F. graminearum & NRRL25797 & NI & Netherlands & AF006344 \\
\hline F.poae & FPU85538 & NI & NI & U85538 \\
\hline F.poae & NRRL25799 & NI & Netherlands & AF006345 \\
\hline F. poae & FRC T-0796 & NI & Japan & AB586983 \\
\hline F. chlamydosporum & CanS-26 & Healthy canola stem & China & JF817304 \\
\hline F. chlamydosporum & 037 & Diseased cocoa tree & Ghina & FJ545407 \\
\hline F. chlamydosporum & $d x-6$ & Unknown mushroom & China & FJ441006 \\
\hline F. chlamydosporum & $\operatorname{Ppf} 29$ & Paris polyphylla Smith var. yunnanensis & China & GU586833 \\
\hline F. oxysporum f. sp. benincasae & NI & NI & China & FJ943656 \\
\hline F. oxysporum f. sp. melonis & NI & NI & NI & AY188919 \\
\hline F. oxysporum f. sp. melonis & ISPaVe1070 & Melon & Italy & FR852561 \\
\hline F. oxysporum f. sp. phase & DM091019-1 & Common bean root & China & HM756257 \\
\hline F. annulatum & $10 p$ & Bean root rot & Mexico & FJ627998 \\
\hline F. oxysporum f. sp. vasin & PA3 & Vitis vinifera & USA & AY462580 \\
\hline F. oxysporum f. sp. сераe & CSC6035ITS & Onion & USA & HQ658961 \\
\hline F. proliferatum & CanR-8 & Healthy canola root & China & JF817300 \\
\hline
\end{tabular}


Table 1. Continued

\begin{tabular}{|c|c|c|c|c|}
\hline Taxon name & $\begin{array}{l}\text { Collection no. } \\
\text { (isolate no.) }\end{array}$ & Source (host) & Origin & $\begin{array}{l}\text { GenBank } \\
\text { accession no. }\end{array}$ \\
\hline F. proliferatum & $\begin{array}{l}\text { ATCC42112 } \\
(=\text { NRRL13569) }\end{array}$ & Zea mays & USA & GQ167231 \\
\hline F. proliferatum & F25 & Cicer arietinum & Mexico & EU091039 \\
\hline F. annulatum & CBS258.54 & NI & NI & AY213654 \\
\hline F. annulatum & NRRL13614 & NI & NI & U61670 \\
\hline F. avenaceum & xsd08063 & Poplar & China & FJ478097 \\
\hline F. avenaceum & MAFF239206 & NI & NI & AB587016 \\
\hline F. avenaceum & F64 & Healthy bulbs of Lilium longiflorum & USA & HQ379700 \\
\hline F. dimerum & CBS110320 & Human toe nails & Chile & EU926273 \\
\hline F. dimerum & CBS116527 & Human, scalp lesion of leukemi patient & USA & EU926284 \\
\hline
\end{tabular}

*Korean strains isolated from C. morifolium. **NI: no information. ATCC: American Type Culture Collection, USA. CBS: Centraalbureau voor Schimmelcultures, The Netherlands. EML: Environmental Microbiology Laboratory Culture Collection, Chonnam National University, Korea. FMR: Facultat de Medicina de Reus Culture Collection, Spain. FRC: Fusarium Research Center, Penn State Univ., USA. MAFF: Ministry of Agriculture, Forestry and Fisheries Culture Collection, Japan. NRRL: Agricultural Research Service (ARS) Culture Collection, USDA, USA. SUF $=$ Culture Collection of Fusarium in Sinshu University, Japan.

alignment length) values were obtained via a NCBI BLASTN search of each isolate. As shown in Fig. 3, identities of EML-CHS1, EML-CHS2 and EML-CH3 isolates were 536/537 (>99\%), 535/536 (>99\%) and 537/ 539 (>99\%) with AM412635, AM412635 and AM412642 retrieved from NCBI, respectively.

Pathogenicity test. To evaluate the pathogenicity of the three Fusarium isolates on C. morifolium (variety Sinro), the isolates were cultivated on PDA and then the spores were harvested. The pathogenicity test was performed using the dipping method. Healthy roots and stems of chrysanthemums were soaked in a conidial suspension adjusted to approximately $3.4 \times 10^{6}$ conidia per $\mathrm{ml}$ (distilled water containing $0.005 \%$ Tween 80 ) for $15 \mathrm{~min}$. The plants were then potted in sterile soil, kept in a humid chamber for 72 hours and finally moved to a greenhouse. The experiment was carried out in duplicate and repeated two times. Ten days after inoculation, similar symptoms to those observed in the greenhouses were seen on the inoculated plants (Fig. 4). The causal fungus was re-isolated from the artificially inoculated basal stems, fulfilling Koch's postulates. No crown rot or wilt symptoms were observed on control plants whose roots and stems were dipped in sterile water. The disease severity was evaluated using a severity score index 3 to 15 days after inoculation. Out of three isolates tested, EML-CHS1 showed the strongest pathogenicity to chrysanthemum (Fig. 4). Inoculated plants resembled those observed on naturally infected plants within 10 days.

It has been shown that chrysanthemums are subject to two vascular wilt diseases caused by $F$. oxysporum f.sp. chrysanthemi and Verticillium dahliae, which persist in the soil for many years. The first signs of Fusarium wilt are yellowing of foliage, stunting, and wilting often along one side of the plant. Plants sometimes appear water stressed and foliage brown and die. In addition, the vascular system of the stems appears a reddish brown color (Agriculture \& Landscape Program, 2011).

On the other hand, symptoms of Verticillium wilt often appear only after blossom buds have formed and young vigorous plants may be symptomless. Foliage becomes yellow and wilted, sometimes only along leaf margins and on one side of the plant. Leaves begin to die from the base of the plant upward and often remain attached. Stems may exhibit dark streaks in the vascular system (Agriculture \& Landscape Program, 2011).

The genus Fusarium including F. solani, has been shown to cause various diseases on a wide range of hosts including Asteraceae (Summerell et al., 2003). Thus far, there have been no reports of Fusarium-induced diseases including crown rot or basal stem rot by $F$. oxysporum or $F$. oxysporum f. sp. chrysanthemi on chrysanthemums in Korea. Only Verticillium wilt by $V$. albo-atrum and $V$. dahliae was reported to occur on chrysanthemums in Korea. To the best of our knowledge, this is the first report of crown rot caused by $F$. solani on chrysanthemums in Korea.

Strider $(1985 \mathrm{a}, \mathrm{b})$ reported that the susceptibility of the chrysanthemum varied with the cultivars. The vast majority of chrysanthemums are highly resistant to both F. oxysporum f. sp. chrysanthemi and f. sp. tracheiphilum; however, Excel, Foxy, Luv, and Fortune are highly susceptible and Applause, Circus, Remarkable, and Tempter are susceptible to $F$. oxysporum f. sp. chrysanthemi. In addition, Foxy was highly susceptible and Luv was susceptible to $F$. oxysporum f. sp. tracheiphilum. Fusarium wilt of chrysanthemums is 


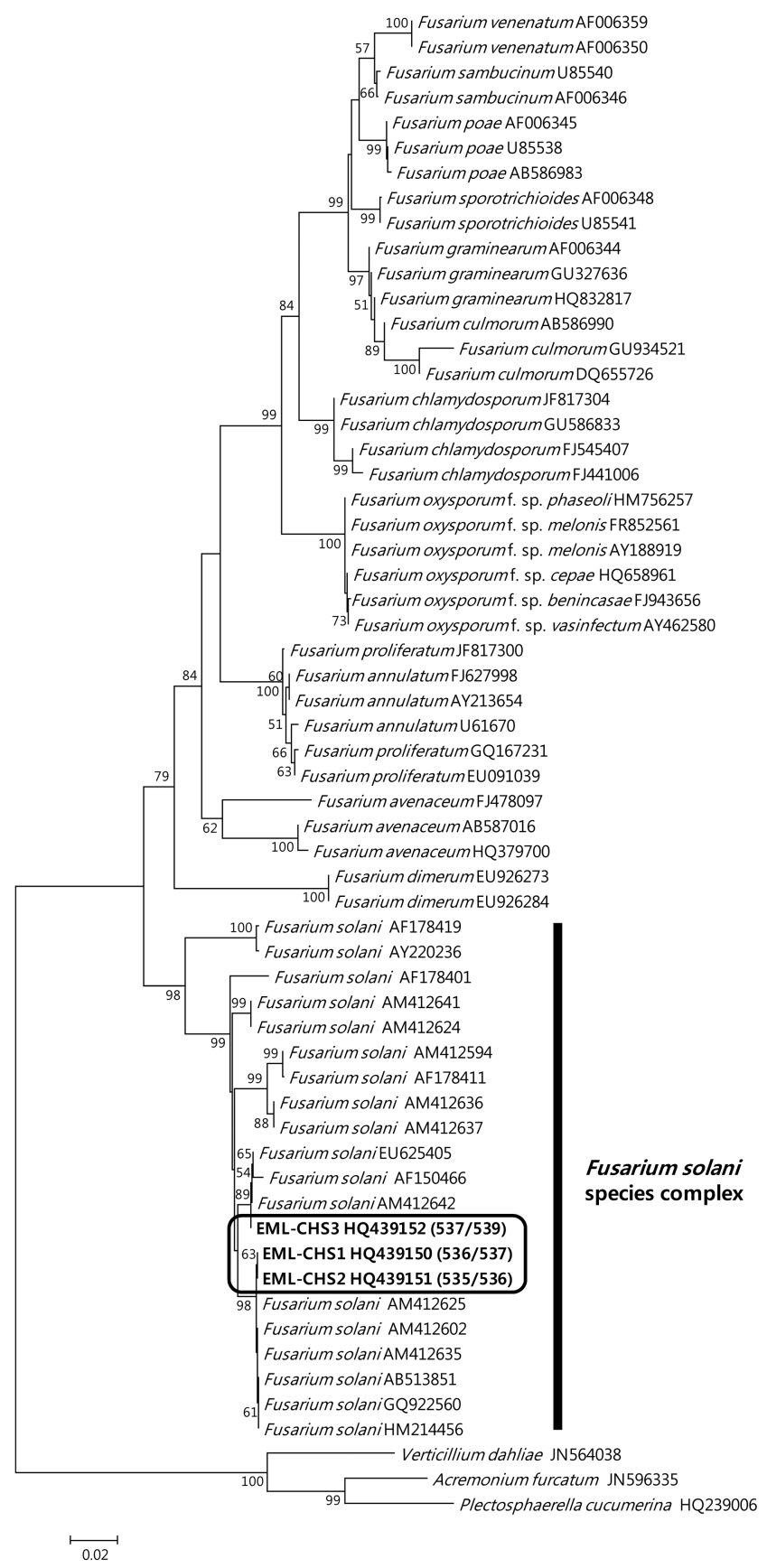

Fig. 3. Phylogentic analysis of the ITS sequences of 60 taxa, including three causal isolates (EML-CHS1, EML-CHS2 and EML-CHS3) obtained from diseased C. morifolium in Korea. The three isolates were observed in this NJ tree relative to other strains of different Fusarium sp. using Verticillium dahliae, Acremonium furcatum and Plectosphaerella cucumerina as outgroups. Bootstrap values were shown above branches supported by more than $50 \%$ from 1,000 replications.

commonly caused by F. oxysporum f. sp. chrynsathemi and F. oxysporum f. sp. tracheiphilum. Fusarium crown rot of chrysanthemums is often difficult to be diagnosed because its symptoms are similar to those caused by nutrient defici-
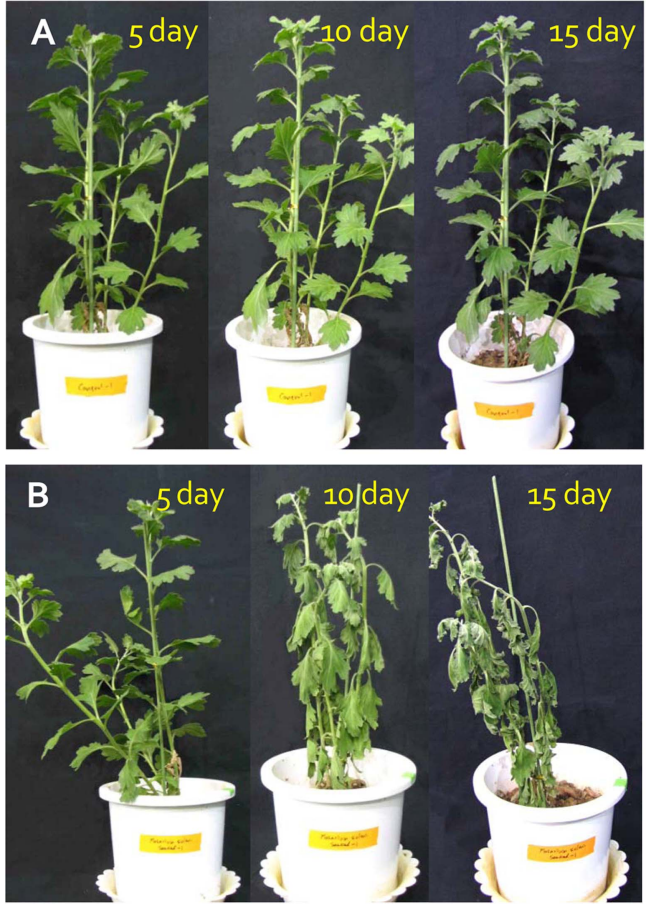

Fig. 4. Pathogenicity of EML-CHS1 on C. morifolium (variety Sinro). (A) control, (B) treated.

encies, improper watering, or diseases such as Pythium root rot or Fusarium wilt (Fisher, 1983; Ren et al., 2008). Fusarium spreads in contaminated soil and infected cuttings and can thrive in warm temperatures, high relative humidity, overwatering, and poor drainage. To manage this disease, pathogen free cuttings or plants are recommended and highly susceptible cultivars should be avoided.

More studies on the ecological characteristics, host range of $F$. solani, relationship between the outbreak of wilt and crown rot and climate change, and appropriate methods to control the diseases on chrysanthemums are needed in future.

\section{Acknowledgements}

This research was supported by the project on survey and excavation of Korean indigenous species of the National Institute of Biological Resources (NIBR) under the Ministry of Environment, Republic of Korea, and NRF grant (20110005264), Ministry of Education, Science and Technology.

\section{References}

Agriculture \& Landscape Program. 2011. Diseases of Chrysanthemum (Chrysanthemum, Dendranthema, Leucanthemum). University of Massachusetts Amherst, Center for Agriculture, UMass Extension, USDA, USA. 
Booth, C. 1971. The Genus Fusarium. pp. 46-53. CMI, Kew, Surrey, UK.

Collins, R. A., Ng, T. B., Fong, W. P., Wan, C. C. and Yeung, H. W. 1997. A comparison of human immunodeficiency virus type 1 inhibition by partially purified aqueous extracts of Chinese medicinal herbs. Life Sci. 60:345-351.

Farr, D. F. and Rossman, A. Y. 2011. Fungal Databases, Systematic Mycology\& Microbiology Laboratory, ARS, USDA, USA. (http://nt.ars-grin.gov/fungaldatabases/).

Fisher, N. L. 1983. Symptom response and colonization as measures of resistance in chrysanthemum cultivars inoculated with Fusarium oxysporum f. sp. chrysanthemi. Plant Dis. 67:376378.

Hu, C. Q., Chen, K., Shi, Q., Kilkuskie, R. E., Cheng, Y. C. and Lee, K. H. 1994. Anti-AIDS agents, 10. Acacetin-7-O-beta-Dgalactopyranoside, an anti-HIV principle from Chrysanthemum morifolium and a structure-activity correlation with some related flavonoids. J. Nat. Prod. 57:42-51.

Lee, H. B., Park, J. Y., Jung, H. S. and Summerbell, R. C. 2006. Phaeomoniella zymoides and Phaeomoniella pinifoliorum spp. nov., new acid-tolerant epiphytic fungi isolated from pine needles in Korea. Mycologia 98:598-611.

Marongiu, B., Piras, A., Porcedda, S., Porcedda, S., Tuveri, E., Laconi, S., Deidda, D. and Maxia, A. 2009. Chemical and biological comparisons on supercritical extracts of Tanacetum cinerariifolium (Trevir) Sch. Bip. with three related species of chrysanthemums of Sardinia (Italy). Nat. Prod. Res. 23:190199.

Nelson, P. E., Toussoun, T. A. and Marasas, W. F. O. 1983. Fusar- ium species. pp. 146-150. The Pennsylvania State University Press, USA.

Ren, Y.-Z., Tan, H., Li, Z.-J., Du, J. and Li, H. 2008. First report of lavender wilt caused by Fusarium solani in China. Plant Pathol. 57:377.

Sassi, A. B., Harzallah-Skhiri, F., Bourgougnon, N. and Aouni, M. 2008. Antimicrobial activities of four Tunisian Chrysanthemum species. Indian J. Med. Res. 127:183-192.

Strider, D. L. 1985a. Fusarium wilt of chrysanthemum: cultivar susceptibility and chemical control. Plant Dis. 69:564-568.

Strider, D. L. 1985b. Fusarium wilt of chrysanthemum: pathogenfree rooted cuttings and susceptibility of new cultivars. Plant Dis. 69:836-838.

Summerbell, R. C and Schroers, H. J. 2002. Analysis of phylogenetic relationship of Cylindrocarpon lichenicola and Acremonium falciforme to the Fusarium solani species complex and a review of similarities in the spectrum of opportunistic infections caused by these fungi. J. Clin. Microbiol. 40:2866-2875.

Summerell, B. A., Salleh, B. and Leslie, J. F. 2003. A utilitarian approach to Fusarium identification. Plant Dis. 87:117-128.

Tamura, K., Dudley, J., Nei, M. and Kumar, S. 2007. MEGA4: Molecular Evolutionary Genetics Analysis (MEGA) software version 4.0. Mol. Biol. Evol. 24:1596-1599.

The Korean Society of Plant Pathology KSPP. List of plant diseases in Korea. 5th Eds., p. 348-351.

Thompson, J. D., Gigson, T. J., Plewniak, F., Jeanmougin, F. and Higgins, D. G. 1997. The Clustal X windows interface: flexible strategies for multiple sequence alignment aided by quality analysis tools. Nucleic Acids Res. 25:4876-4882. 